\title{
Das neue Instrument
}

\author{
Koaxiale oder kolineare „Schiebezange“
}

\section{Dankward Höntzsch}

Im Rahmen der Entwicklung von Instrumenten und Implantaten zur minimalinvasiven Osteosynthese wurde von der AO in Zusammenarbeit mit der Universitätsklinik Basel (Prof. Dr. Regazzoni u. Mitarb.) und der Mathys AG eine Schiebezange entwickelt, welche nicht quer, sondern in längs verlaufender Achsenrichtung zusammengeschoben wird. Der Vorschub wird über einen Griff erzielt, wie er in der Technik z. B. bei Silikonpressen seit langem bewährt ist.

An den Griff können verschiedene Formen des Schiebeteils sowie des umgreifenden Armes angedockt werden. Hierdurch wird ein breites Spektrum abgedeckt.

Speziell die schlank und koaxial schiebende Zange ist geradezu ideal für Repositionen am Becken durch konventionelle und durch minimierte Zugänge. Die Indikation ist überall dort gegeben, wo quer zur Kompressionsrichtung abstehende Griffe nicht zur Anwendung kommen können.

Eine Hauptindikation ist die Reposition im Bereich der Linea terminalis und kaudal davon am Becken gegenüber der Crista (siehe Abbildungen).

In allen Testkliniken und bei allen Chirurgen, welche die Zange ausprobieren konnten, war der Mechanismus bei jedem Einsatz einfach und selbsterklärend angesehen worden. Die Zange war in jedem Fall sehr hilfreich. Damit sind Repositionsmanöver möglich, die bisher so nicht oder nur sehr schwer durchgeführt werden konnten.

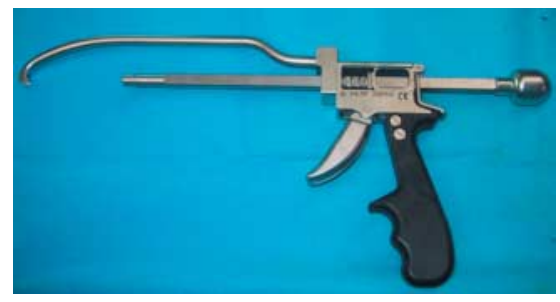

Abb.1 Die koaxiale Zange mit dem schlanken Bügel.

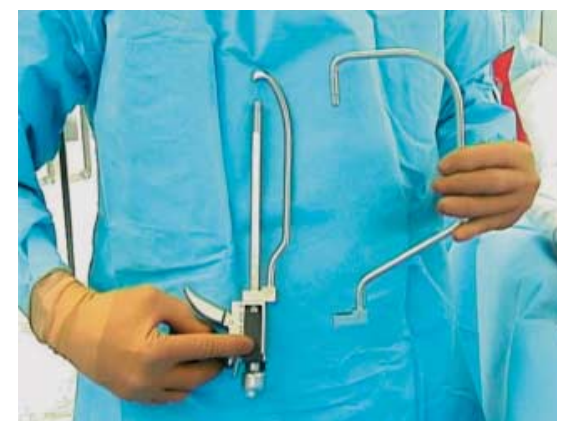

Abb. 3 Es sind verschiedene schlanke und ausladende Bügel verfügbar.

Die Zange eignet sich auch zur reponierenden Kompression außerhalb des Beckens, z. B. im Bereich der Kondyle (Abbildung), am Tibiakopf und an der distalen Tibia. Der schiebende Anteil ist kanüliert, so dass ein Kirschner-Draht vorgebracht werden kann, über welchen dann kanülierte Schrauben eingebracht werden.

Die module Bauweise erlaubt es, dass in naher Zukunft weitere Zangenteile angeboten werden. Hierzu werden dann auch Zangen gehören, welche von beiden Seiten kanüliert sind (z.B. für die Fuß- und Fersenbeinchirurgie).

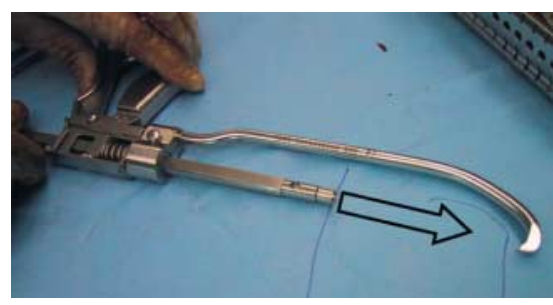

Abb. 2 Der Pfeil zeigt die Schieberichtung an.

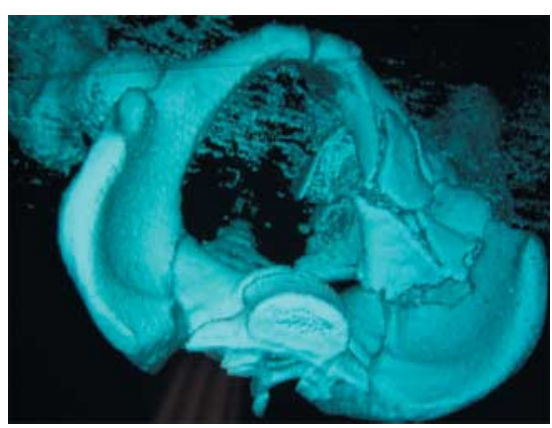

Abb. 4 3D-CT einer Azetabulumtrümmerfraktur rechts.

Von Seiten unserer Tübinger Erfahrungen fragt man sich, warum es solch eine Zange nicht schon lange gibt und wir prophezeien dieser Zange eine große Zukunft.

PS: Der Autor ist nur Berichterstatter und konnte die Zange in der Testphase benutzen, er ist nicht Entwickler. 


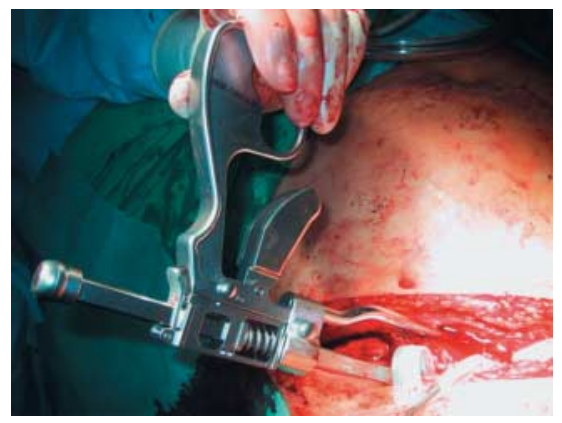

Abb. 5 Einsatz der Zange durch einen inguinalen Zugang.

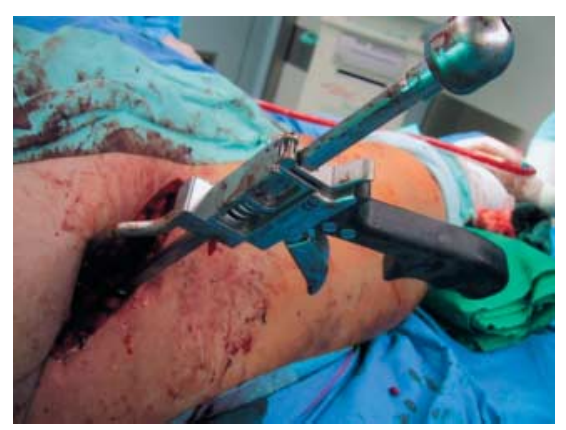

Abb. 8 Weiteres Beispiel einer Zangenposition durch inguinalen Zugang.

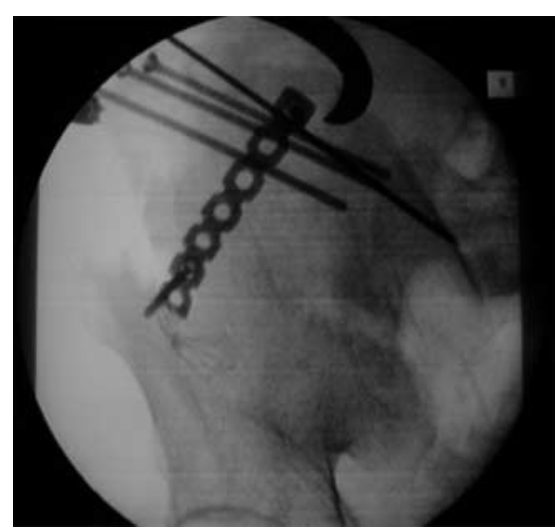

Abb.11 Weiteres Röntgenbeispiel.

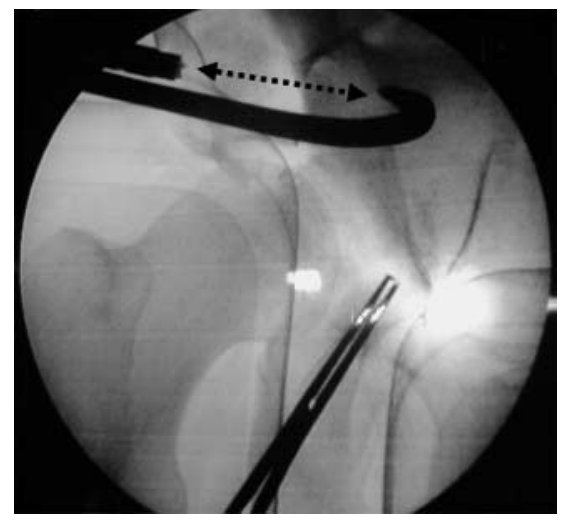

Abb. 6 Röntgenbild, welches das Einhaken und die Schieberichtung anzeigt.

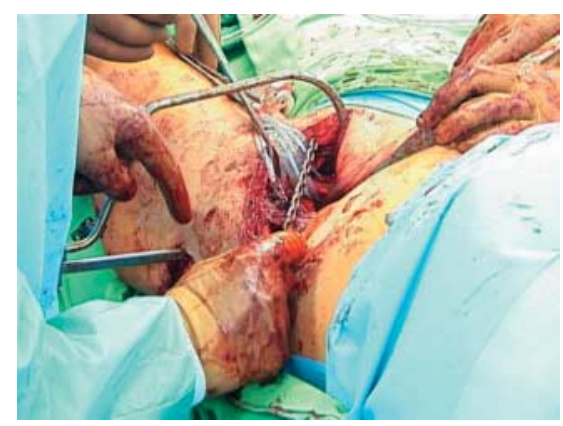

Abb.9 Die Zange erlaubt auch spezielle schiebende Repositionsmanöver, z. B. vom Schambeinast zur äußeren Beckenschaufel.

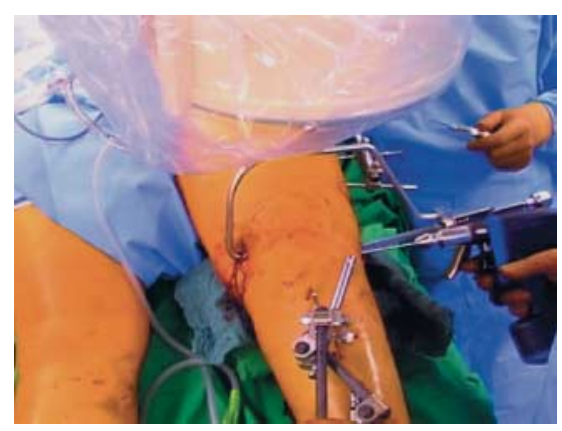

Abb.12 Koaxiale Zange mit großem Bügel zur streng queren reponierenden Kompression im Bereich der Oberschenkelkondyle.

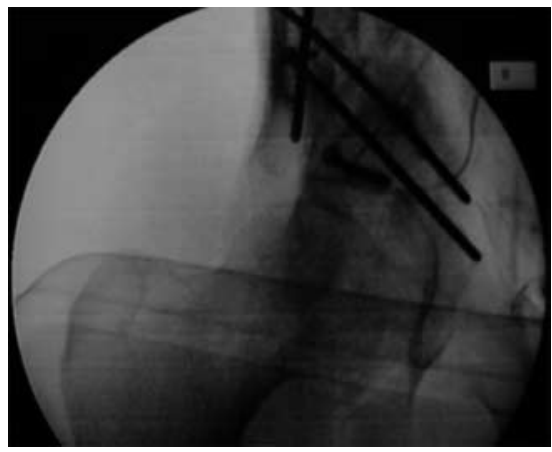

Abb.7 Schraubenosteosynthese der Azetabulumfraktur.

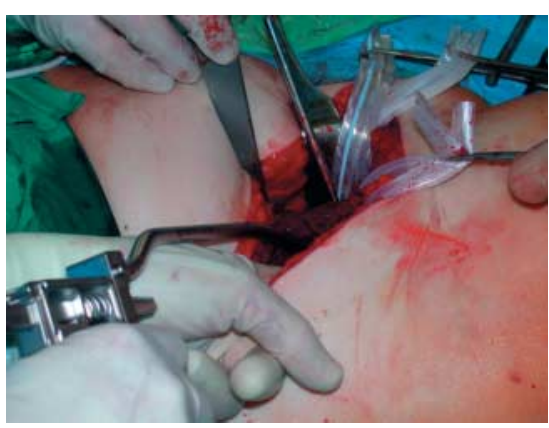

Abb.10 Die Gegenspitze kann vorsichtig mit dem Finger eingeführt werden.

Prof. Dr. med. Dankward Höntzsch Leitender Arzt

BG Unfallklinik

Schnarrenbergstr. 95

D-72076 Tübingen 